\title{
SPECTROSCOPY IN AUSTRALIA
}

$\mathrm{T}$ HE fifth Australian Spectroscopy Conference, sponsored by the Spectroscopy Committeo of the Australian. Academy of Science and organized by a Committee under the chairmanship of Dr. A. R. H. Cole, was held at Perth, at the University of Western Australia, during May 31June 2.

The Conference was opened by Dr. A. L. G. Rees, who welcomed those attending of whom fourteen were from overseas. The programme consisted of morning and afternoon sessions on each of the three days, usually with concurrent lectures on topies in different sections of spectroscopy The sections were infra-red and Raman spectroscopy; visible, ultra-violet and theoretical spectroscopy, nuclear and electron spin resonance spectroscopy; atomic absorption spectroscopy; mass spectroscopy and $\mathrm{X}$-ray fluorescence and electron absorption spectroscopy. More than eighty-five papers were presented, of which nine were review papers by invited speakers.

The section on infra-red and Raman spectroscopy opened with a review paper given by Prof. N. S. Sheppard (University of East Anglia) on infra-red band shapes and rotational motion in condensed phases. It was shown that simple molecules such as methyl chloride undergo at least hindered rotation in solution while molecules adsorbed on to surfaces may rotate about the bond linking the molecule to the surface.

The first of the succeoding papers of this section was a report by A. D. E. Pullin (Monash University) on the operation of a commercially made interferometer designed to measure infra-red spectra down to $20 \mathrm{~cm}^{-1}$. A brief outline of the theory of operation and the factors determ. ining spectral range and resolution was given. Examples of spectra obtained were shown.

Several succeeding papers discussed the use of infra-red and Raman spectra to assign particular molecules to their correct point group or to indicate preferred conformations of flexible molecules. J. F. Horwood (C.S.I.R.O., Division of Dairy Research, Melbourne) and J. K. Wilmshurst (C.S.I.R.O., Division of Chemical Physies, Melbourne) suggested that dimethyl oxalate in the liquid and vapour phases was non-planar with point group symmetry $\mathrm{C}_{2}$. E. Spinner (Australian National University) reported Raman polarization data for aqueous solutions of formates and pointed out that these were consistent with $\mathrm{C}_{s}$ rather than $\mathrm{C}_{2} v$ symmetry for the formate ion. N. S. Ham (C.S.I.R.O., Division of Chemical Physics, Melbourne) discussed the spectra of thionyl aniline, $\mathrm{C}_{6} \mathrm{H}_{5} \mathrm{NSO}$, and showed that it was consistent with a cis planar CNSO structure though the trans structure could not be eliminated. R. A. Cummins (Defence Standards Laboratories, Melbourne) discussed the preferred conformations present in alkyl tin compounds of the type $R_{n} \mathrm{SnCl}_{4^{-n}}$, and H. Lee and J. K. Wilmshurst (C.S.I.R.O., Division of Chemical Physics, Melbourne) the conformations of trimethyl orthoformate and tetramethyl orthocarbonate. The vibrational data are consistent with an unsymmetrical trans-gauche-gauche arrangement of the methyl carbons with respect to the formate hydrogen in trimethyl orthoformate and with a distorted $\mathrm{S}_{4}$ structure for the tetramethyl carbonate.

In a second paper concerned with the infra-red spectra of several acetates (hydroxyanthraquinone acetate, phenyl acetate, $\alpha$ and $\beta$ naphthyl acetates) these authors attribute the observed doubling of the carbonyl stretching absorption to Fermi resonance with combination tones. A. R. H. Cole and L. M. Engelhardt (University of Western Australia) analysed the rotational fine structure of several bands of acrolein in terms of an approximate symmetric top and showed that the data are consistent with the existence of only the trans form. Analyses of vibrationrotation bands of methylphosphine and isotopic deriva- tives, which are also approximate symmetric tops, leading to values of $\frac{1}{2}(B+C)$ in agreement with microwave data were reported by A. G. Moritz (Defence Standards Laboratories, Melbourne). In a later paper A. G. Moritz discussed the vibrational assignment of $\mathrm{CH}_{3} \mathrm{SCN}$ and related molecules. G. C. Barraclough and M. Sinclair (University of Melbourne) discussed the vibrational assignment of dicarbonyldinitrosyl iron, and D. E. Clegg (University of Queensland) that of $\left(\mathrm{CH}_{3}\right)_{3} \mathrm{Pt}\left(\mathrm{NH}_{3}\right)_{3}^{+}\left(\left(\mathrm{CH}_{3}\right)_{3} \mathrm{Pt}\left(\mathrm{NH}_{3}\right)_{3} \mathrm{Cl}\right.$ in water and deuterium oxide). M. S. Farrell and T. L. Whateley (A.A.E.C. Research Establishment, Lucas Hoights) reported the infra-red spectra of beryllium nitrate complexes with organo-phosphorus compounds such as tri- $n$-butyl phosphate, tri- $n$-octyl phosphine oxide and di-(2-ethylhexyl)-phosphoric acid. B. H. James and P. E. Rogasch (Weapons Research Establishment, Adelaide) discussed the changes of the in-plane bending froquencies of substituted phenols with respect to electronic effects and hydrogen bond formation, and R. $\mathrm{H}$. Laby (Department of Agriculture, Melbourne) and T. C. Morton (School of Biochemistry, University of Melbourne) discussed inter-and intra-molecular hydrogen bonding in hydroxy-and nitro-hydroxy-coumarins.

Three papers on the use of infra-red spectroscopy in adsorption studies were presented: M. Clark, B. A. Morrow, N. Sheppard and J. W. Ward (University of Cambridge and the University of East Anglia) discussed the infra-red spectra obtained from the examination of the systems olefine-silica supported nickel (or supported platinum-hydrogen; N. W. Cant and L. H. Little (University of Western Australia) the spectra for ammonia and deutero ammonia adsorbed on silica; and W. I. Stuart and T. L. Whateley (A.A.E.C. Research Establishment, Lucas Heights, N.S.W.) the spectra of carbon monoxide, of carbon dioxide, and of water on magnesium oxide and on beryllium oxide. Below $200^{\circ} \mathrm{C}$ carbon dioxido is chemisorbed on beryllium oxide, to form a carbonate and also a singly charged anion, probably $\mathrm{CO}_{3}$. Above $300^{\circ} \mathrm{C}$ only the carbonate is formed.

Several infra-red investigations of compounds of biological interest were described. A. J. Michell described polarized infra-rod studies of some monosaccharides, related to cellulose and xylan, which were chosen because their crystal structures had been investigated and because they were more easily crystallizable than higher members of the sugar series. E. G. Bendit (C.S.I.R.O., Division of Toxtile Physics, Sydney) discussed the changes of the infra-red spectra of $\alpha$ - and $\beta$-keratin of horse-tail hair on hydration and deuteration. Deuteration tests on $\alpha$-keratin showed that helical peptide $\mathrm{NH}$ groups begin to deuterate immediately, while non-helical peptide NH groups continue to exchange throughout the process. R. D. B. Fraser and E. Suzuki (C.S.I.R.O., Division of Protein Chemistry, Melbourne) considered the roles of inter- and intra-molecular hydrogen bonds in modifying the characteristic vibrations of polypeptides. In an interesting paper R. H. Laby (Department of Agriculture, Melbourne) discussed the infra-red spectra of glycine, glycylglycine and $\beta$-alanine in aqueous salt solutions and related spectral changes to conformational changes brought out by differing salt solutions.

Two interosting papers in this section were contributed by visiting Indian scientists. Prof. R. S. Krishnan (Indian Institute of Science, Bangalore) gave an account of the theory of Raman spectra of cubic diatomic crystals; and Prof. C. N. R. Rao (Indian Institute of Technology, Kanpur), in a paper on charge transfer and hydrogenbonded complexes of $n$-donors, surveyed correlations of spectroscopic and thermodynamic data with substituent effects and other structural parameters. Also concerned with complexes of the charge-transfer type was a paper by 
N. F. Cheetham and A. D. E. Pullin (Monash University), who described an infra-red study of molecular complexes between perfluoroalkyl bromides (and iodides) or perfluoroaryl bromides (or iodides) and tertiary amines. The stoichiometry of the complexes had been previously determined by phase studies.

Of wide interest was a paper by G. R. Hunt and J. W. Salisbury (Lunar and Planetary Research Station, Bedford, Massachusetts) on the infra-red techniques used in an attempt to gain information about the silicates present in selected areas of the Moon's surface. These techniques were based on selective reflexion of the radiation by silicates of the various chemical types that might be present on the Moon's surface. A standard spectrometer, suitably modified, was used in conjunction with 42-in. and 69-in. reflecting telescopes.

Many of the papers presented in section $B$, that on visible, ultra-violet and theoretical spectroscopy, reflected the present-day strong interest in problems peculiar to transitions in condensed phases on one hand, and on the other to the new problems that obtrude when the spectra of larger molecules are examined in the vapour phase by high resolution methods.

Prof. D. P. Craig (University College, London), in an invited paper, roviewed the recent advances in the theory of molecular excitons. Prof. Craig described first the modifications of the theory of crystal spectra consequent on taking into account the finite time of propagation of electrical fields in solids, and then discussed, among other topics, how application of theory to crystal spectra could give information on long-range interactions between molecules. Prof. Craig ended his lecture by showing how information about the degree of order in melts could be obtained from their electronic spectra, taking azulene as his example. In a subsequent paper R. G. Body (University of Sydney) gave the results of a mathematical investigation, based on the principles of coupled oscillators, of the positions and polarization of absorptions in crystals due to impuritios. Approximate formulae derived enabled the normalized second moment of the energy-level distribution in the pure crystal to be deduced from the spectra of isotopic impurities. Under certain conditions non isotopic impurities can display striking intensity anomalies. The theme of solid-state spectra was also the subject of papers by G. W. Robinson (California Institute of Technology) on $\epsilon x c i t o n$ structure in benzene, who gave experimental data on the exciton splitting in the benzene ${ }^{1} B_{2 \mu}$ electronic state and in a number of vibrational levels in the ground electronic state, and by M. Chowdhury, D. McClure and E. Zalewski (University of Chicago), who described an investigation of the Zeeman effect on the singlet triplet spectrum of pyrazine. Single crystals at $\sim 4^{\circ} \mathrm{K}$ and pulsed magnetic fields up to 200,000 gauss were used. Two bands, believed to be two Davydov components, at 26,254 and $26,261 \mathrm{~cm}^{-1}$ were assigned, from their polarization and Zeeman effect characteristics, to an electric dipole transition along the $\mathrm{N}-\mathrm{N}$ axis and to a magnetic dipole transition respectively. Later in the Conference, in an invited address, Prof. McClure described the way in which spectroscopic states of various ions are split when they are subjected to crystal fields of cubic lower symmetry. Ho illustrated this for various transition elements and rare earth ions, and showed how some complex crystal spectra yieldod to this form of analysis. B. N. Figgis and L. G. B. Wadley presented preliminary polarization data on a charge transfer band at about $24,000 \mathrm{~cm}^{-1}$ in dilute solid solutions of potassium ferricyanide in potassium cobalt cyanide. Several papers concerned with solvent effects on electronic bands were presented. N. S. Bayliss and G. Wills-Johnson (University of Western Australia) examined the effect of solvents on the intensities of electronic bands of molecules in solution by perturbation methods, deriving the perturbation from the solvont reaction field. The shortcomings of, and possible improvements to, this approach were outlined.
The predictions of the theory were compared with experimental results for the $n \rightarrow \pi^{*}$ transitions in aliphatic ketones and nitroparaffins in solution. D. W. James (University of Queensland) and C. R. Boston and G. P. Smith (Oak Ridge National Laboratory, U.S.A.) described the effects of change of tomperature and change of cationic species on tho weak band at $\sim 195 \mathrm{m \mu}$ and the strong band at $\sim 300 \mathrm{~m} \mu$ in molten nitrates in terms of coulomb interactions, variations in environmental symmotry and variation in vibrational energy.

The third invited speaker was Dr. D. A. Ramsay (National Research Council, Ottawa). Dr. Ramsay began his address by pointing out that in general, in electronic spectra, doppler motion broadens lines sufficiently to limit useful resolution to one in half a million, a natural limit attained by the best presont-day spectrographs. For larger molecules, the lines of which are closer than this, the observed band contour can be comparod with contours computed from overlapping line intensities. (Later in the conference the application of this procedure to part of the azulene spectrum was described by A. J. MeHugh of the University of Sydney.) Dr. Ramsay then turned his attention to spectra of smaller molecules recently obtained at the Ottawa laboratories. The structures of glyoxal in the ground and excited states were being deduced from its spectra. Preliminary estimates of bond-lengths for the first excited singlet state were in agreement with predictions of molecular orbital theory for conjugated molecules of this type (glyoxal, butadiene, etc.). After reference to recently obtained spectra of the allyl and glyoxal radicals, Dr. Ramsay described techniques being developed at the Ottawa laboratories to aid the analyses of spectra. The ' $J$ sorting' technique was based on the injection of microwave power to disturb the rotational levels of one of the combining states. This technique was limited to molecules having a microwave spectrum. In a later paper with Prof. A. D. Buckingham (University of Bristol), Dr. Ramsay described experiments carried out at the Ottawa laboratories on the use of Stark modulation to help identify the type of transitions. An alternating voltage was applied to the plates of a Stark cell at $400 \mathrm{c} / \mathrm{s}$ and the Stark-modulated spectrum recorded at high resolution with the photomultiplier detector connected to a lock in amplifier tuned to $800 \mathrm{c} / \mathrm{s}$ so that only lines with appreciable Stark effect were recorded. Up to $80 \mathrm{kV}$ was applied across the $3-\mathrm{cm}$ width of the $2-\mathrm{m}$ long cell. A relatively high pressure $(\sim 300 \mathrm{~cm})$ of $\mathbf{S F}_{6}$ was introduced in the cell to prevent electrical breakdown. For a symmetric top the Spark splittings are dopendent on $\mu K M / J(J+1)$ so that Stark modulation favours the selection of lines of higher $K$ and lower $J$ values. By use. of polarized light the $Q$ lines can be identified as those more prominent in parallel polarization and those more prominent in perpendicular polarization as $P$ and $R$ lines. As well as helping to assign lines as $P, Q$ or $R$, dipole moments of molecules in excited states could be obtained from Stark splittings.

In the field of vapour phase aromatic spectra G. C. Morris (University of Melbourne) presented results on band positions, oscillator strengths and assigned transitions for the region $20,000-54,000 \mathrm{~cm}^{-1}$ of the absorption spectra of naphthacene. J. P. Byrne and I. G. Ross (University of Sydney) considered the cause of spectral diffuseness: not all diffuseness is due to predissociation; plain congestion of the spectrum can be a cause in larger molecules. L. M. Logan and I. G. Ross (University of Sydney), in a paper concerning molocular fluorescence in the vapour stato, considered the interaction between the original excited vapour stato and the vibronic states of the lowor electronic levels. R. H. Kennet (Weapons Research Establishment, Adelaide) described a method for the determination of the intensity distribution in an unresolved molecular band, and described features of the profile that are dependent only on tomperature and from which the tomperature may be deduced. 
In an interesting paper C. E. Kendall (National Biological Standards Laboratory, Canberra) attempted to delineate more closely the possible connexion between the carcinogenic activity of molecules and their electron donor characteristics by using experimental data and energies of the highest occupied molecular orbitals of the donors to prepare a common index of donor activity for comparison with charge transfer data. Whon this comparison is made--for example, in the form of a plot-complexes of nearly all carcinogens lie in a fairly narrow range, especially when the common acceptor is chloranil. Possibly some type of electron transfer may be involved in a cell, with an electron acceptor of similar affinity to chloranil. B. K. Selinger (School of General Studies, Canberra) in a paper on excimer formation described an investigation of the effect of pressure on the kinetics of formation of excited dimers by molecules in the excited state. Whero the activation energy of dimer formation is low, the increase in viscosity with pressure does not affect the process and the decrease in volume accompanying excited dimer formation can be measured.

The diversity of uses of spectroscopic techniques was exemplified by a paper by K. J. Taylor and P. D. Jarman (University of Western Australia) on an aspect of sonoluminescent spectra. When cavities in liquids, produced ultrasonically, collapse, thermally excited radiation is emitted. If the liquid contains a dissolved alkali metal salt, the alkali lines appear in emission displaced and much broadened by interactions with the cavity contents. From these data the relative density of the cavity contents at the time of light emission can be calculated.

Instrumental aspects of spectroscopy were represented by sevoral papers. Dr. S. E. Williams (University of Western Australia), in a review of the development of spectroscopy in the spectral range $1000-20 \AA$, described the many experimental problems encountered and showed examples of spectra in this region. Dr. Williams emphasized the importance of isoelectronic sequences in the interpretation of such spectra. S. C. Baker (University of Newcastle) described an Ebert-type scanning spectrometer with a resolving power of 500,000 in the tenth order green, and $K$. J. Taylor and P. D. Jarman described an autospectrophotometer for a low-intensity source. The prism can be rotated in either direction in steps by a motor driven by electric pulses derived from a logic eircuit which also addresses the integrated output pulses from the photomultiplier into a 400-channel analyser. The memory of the analyser can then be read out as desired.

In a paper on the electronic emission spectrum of the diatomic molecule IF, R. A. Durie (C.S.I.R.O., Division of Coal Research, Sydney) summarized the analysis of the $A^{\prime} \Sigma \rightarrow X_{\pi 0}^{3}$ transition and the derived molecular constants. C. Candler (Bendigo Technical College, Bendigo) prosented a papor on the mechanism of dye sensitization of photographic emulsions.

Two other invited review papers rolated to electronic spectroscopy were given during the conferenco. Dr. Wilse Robinson (California Institute of Technology) gave a stimulating account of photosynthesis from a spectroscopist's point of view, stressing the essentials and the two-quanta process involved; and Prof. R. D. Brown (Monash University) outlined the best methods now available for calculating the energies of excited states of molecules. Introduction of configuration interaction led to a large number of integrals. Their number could bo reduced by the approximation of zero differential overlap. Improved energies could be obtained by somi-empirical corrections to decrease nearest neighbour repulsion integrals to allow for the offects of electron correlation. Prof. Brown ended his address by showing how the calculated energies of the electronic states of benzene varied according to which of the up-to-date methods of correcting these integrals was adopted.

Two papers in this section formed a close link with those in the mass spectroscopy section. J. D. Morrison.
(C.S.I.R.O., Division of Chemical Physics, Melbourne) discussed the application of extended Hückel type cal. culations on simple molecules to determine if possible the location from which an electron will be ionized and, if the resultant ion dissociated, the most probable fragments and their structures, and A. J. C. Nicholson (C.S.I.R.O., Division of Chemical Physies, Melbourne) reported an investigation of photo-ionization efficiency curves. Ionization potentials of methane, ethane and propane, claimed to be closer to the adiabatic values than those extant, were reported, and it was shown how, from a comparison of photo-ionization efficiency curves, it is possible to identify vibrational and excited states of specific molecular ions.

Section $C$, dealing with nuclear and electron spin resonance spectroscopy, covered a fairly wide range of interests despite the small number of papers presented.

The analysis of high-resolution nucloar magnetic resonance spectra was considered in a paper by S. N. Stuart (C.S.I.R.O., Division of Chemical Physies, Melbourne), who showed how it was possible to systomatize the use of quantum mechanical trace relations in such analyses and illustrated some of the simplifications thus arising.

In the field of proton resonance spectroscopy, the paper by P. J. Black, R. D. Brown and M. L. Heffernan (Monash University) showed how it was possible, after appropriate corrections had been applied, to correlate proton shifts with molecular orbital electron densities of aromatic heterocycles. R. G. Gillis (Defence Standards Laboratories, Victoria) and N. S. Ham (C.S.I.R.O., Division of Chemical Physics, Melbourne), in studies on a number of methyl-sulphur compounds, used the relation between proton chemical shifts and ${ }^{13} \mathrm{C}-\mathrm{H}$ coupling constants to estimate the anisotropy effects present in these substances. The effectiveness of natural abundance ${ }^{13} \mathrm{C}$-nuclear magnetic resonance spectroscopy as a tool for tho analysis of coal derivatives was well illustrated in the paper by $\mathbf{R}$. A. Friedel and H. L. Retcofsky (Bureau of Mines, Pittsburgh Coal Research Centre).

Broad line NMR was well represented by three papers. C. K. Coogan (C.S.I.R.O., Division of Chemical Physics, Molbourne) discussed the investigation of charge distributions in the ionic crystals $\mathrm{LiOH}$ and $\mathrm{NaSH}$ and showed how a number of other crystal properties could be investigated with NMR. A similar investigation of ionic crystal with a linear triatomic anion was reported by I. D. Campbell (C.S.I.R.O., Division of Chemical Physies, Melbourne). G. J. Jenks (Defence Standards Laboratories, Melbourne) demonstrated the use of tin and nitrogen resonances in the assignment of a structure to tri-nbutyltin thiocyanate and reported the presence of an ${ }^{119} \mathrm{Sn}-{ }^{15} \mathrm{~N}$ coupling constant.

Electron spin resonance spectroscopy was ropresented by one paper. K. Kenny (Washington University, St. Louis, U.S.A.) indicated how the use of multi-channel analyses has facilitated the detection of transient free radicals. The application of the technique to living aquarium plants was described.

The section on atomic absorption revealed exciting developments in all aspects of the field. In his invited contribution, A. Walsh (C.S.I.R.O., Division of Chemical Physics, Melbourne) described the successful development by him and his colleagues of several new systems for enhancing and isolating resonance radiation. These include a hollow cathode lamp having a subsidiary discharge that selectively intensified resonance lines 100-fold without increasing line width, and resonance monochromators that can be used both with conventional and high-intensity lamps and that offer the possibility of simultanoous determination of a number of elements. A. Hell (Beckman Instruments, U.S.A.) discussed the optical and mechanical factors involved in obtaining optimum performance from a laminar flow burner and described means of extending analytical range by the use of an infra-red heated spray chamber and solvent conden- 
sation system. The addition of 12 elements to those previously determinable in aqueous solution and a general alleviation of chemical interference by the use of hightemperature flames employing $\mathrm{O}_{2}-\mathrm{N}_{2}$ mixtures and $\mathrm{N}_{2} \mathrm{O}$ with acetylene was revealed by J. B. Willis (C.S.I.R.O., Division of Chemical Physics, Melbourne) in a joint paper with M. D. Amos (Techtron, Victoria). In another paper, J. B. Willis stated that examination of atomizer design has resulted in considerable improvement in performance being achieved by precision in construction and by providing means of accurately positioning the capillary. J. V. Sullivan (C.S.I.R.O., Division of Chemical Physics, Melbourne) discussed the construction and performance of high-intensity lamps. The increase in the intensity of the resonance lines has been achieved by exciting the metal atoms, produced by a hollow-cathode discharge with a secondary discharge electrically isolated from the former. He then described a high-intensity lamp which incorporates an additional hollow cathode which selectively modulates the resonance lines and permits the use of low-resolution monochromators for the isolation of resonance lines in complex spectra. W. Slavin (Perkin-Elmer, U.S.A.), in tracing the development of burners, described a design having multiple slots for producing an $\mathrm{N}_{2} \mathrm{O}-\mathrm{C}_{2} \mathrm{H}_{2}$ flame of high temperature and stability by the operation of sheathing flames on each side. Examination of the performance of this burner has shown that good agreement with other methods is obtained, that a number of transitions from excited states absorb and that phosphate enhances vanadium absorption. Mrs. J. A. Bowman (C.S.I.R.O., Division of Chemical Physics, Melbourne), in collaboration with J. C. Heerdt (Commonwealth Railways, Port Augusta, South Australia) and J. B. Willis, reported that good agreement could be obtained between atomic absorption measurement on oil dissolved in 2-methyl-4-pentanone and both atomic absorption and colorimetric results on dissolved ash for $\mathrm{Cu}, \mathrm{Cr}, \mathrm{Fe}, \mathrm{Pb}$ and $\mathrm{Ag}$, but it was agreed in discussion that the greatest hazard in diagnosis of engine breakdown lies in the sampling of the oil. N. J. Marshall (Bureau of Mineral Resources, Canberra) reported success in the extraction of various substituted thiocarbamate complexes of $\mathrm{Cu}$, $\mathrm{Pb}, \mathrm{Ni}, \mathrm{Co}$ and Te into amyl acetate for the determination of these elements, at parts-per-hundred-million levels, in rocks by atomic absorption; and D. C. Bowditch, jointly with J. A. Powell (both of the Australian Mineral Development Laboratories, Adelaide), that atomic absorption could compete favourably with other means of analysis in the determination of $\mathrm{Cu}, \mathrm{Zn}, \mathrm{Co}, \mathrm{Ni}, \mathrm{Cd}, \mathrm{Mn}, \mathrm{Sb}, \mathrm{Ag}$ and $\mathrm{Bi}$ both at low concentration in goochemical and mill tailing samples and at high concentration in mill feed and product control. After outlining his methods of soil and plant analysis for some 25 major and minor elements by means of flame emission, porous cup spark emission, rotating disk spark emission on a direct reader and chemical concentration followed by cathode layer arc emission (improved by image converter scanning of plates), R. L. Mitchell (Macaulay Institute for Soil Research, Scotland) described, in an invited address, an atomic absorption method for the determination of extractable cobalt at deficiency-levels in soils, stating that considerable gain in sensitivity had recently been achieved by use of a special atomizing systom, tuned a.c. amplifier and recorder read-out.
A successful mass spectrometry seetion was a late addition to the Conference programme. Seven papers were presented; six of these, including an introductory lecture by J. S. Shannon (C.S.I.R.O., Division of Coal Research, Sydney), dealt with structural applications in organic, metal-organic and co-ordination chemistry, and the seventh with an electric quadrupole mass spectrometer (D. Swingler, C.S.I.R.O., Division of Chemical Physies, Melbourne). The structural applications reported included a structural assignment for the complex fungal metabolite sporidesmin $C$, a tentative structure for the cell growth factor 'Zeatin', a characteristic reaction of 2,5-diaryl oxazole systems in which CO and HCN is eliminated (W. D. Crow, J. Hodgkin, R. Hodges, D. Letham and J. S. Shannon), structures for the Schiff Base bisbenzoylacetone-ethylenediimine and its metal chelates, and the mass spectra of $\mathrm{Ph}_{\mathbf{3}} M(M=$ $\mathrm{N}, \mathrm{P}, \mathrm{As}, \mathrm{Sb}, \mathrm{Bi}$ ) and rolated compounds (J. S. Shannon) and of macrorungia alkaloids (R. R. Arndt, K. Biemann, A. Jordaan, V. P. Joynt and J. L. Occolowitz (C.S.I.R.O., Division of Chemical Physics, Melbourne). N. Wasada and I. Tsuchiya (Government Chemical Industrial Research Institute, Tokyo), E. Yoshii (Faculty of Pharmaceutical Sciences, University of Toyama, Japan), T. Fukuzumi (Japan Monopoly Corporation) and E. Watanabe (Japan Electron Optics Laboratory) reported on fragmentation patterns and discussed their mechanisms for santonins and their derivatives and also for solanone, an unsaturated branched aliphatic ketone from tobacco leaf. J. L. Occolowitz (Defence Research Laboratories, Melbourne) and J. M. Swan (C.S.I.R.O., Division of Organic Chemistry, Melbourne) described the mass spectra of phosphonic esters $R . \mathrm{PO}\left(\mathrm{OR}^{\prime}\right)_{2}$ and dichlorides $R \mathrm{POCl}_{2}$, and emphasized the value of keeping an accurate electron balance in the formulation of ionic equations. General patterns for the decomposition of odd electron (radical) ions and even electron ions were described. In a stimulating discussion of these papers the approach of the organic chemists to the interpretation of mass spectra was criticized as lacking quantitative energy factors; in reply it was maintained that, provided the approach was utilized correctly, there was at present no better method available.

The remaining section of the Conference consisted of four papers on X-ray spectroscopy. D. McKenzie (Aus. tralian Iron and Steel, Wollongong, N.S.W.) described the analysis of coals by X-ray spectroscopy, and in a paper by K. Norrish (C.S.I.R.O., Division of Soils, Adelaide) a technique for silicate analysis was described in which the sample was fused with lithium borate glass, with added lanthanum oxide and cast in a penny-shaped disk. Advantages of this technique include durability of sample and uniform background. K. Norrish and C. G. Gurr (C.S.I.R.O., Division of Soils, Adelaide) described an automatic pulse-height analyser for use in X-ray spectrography, and J. B. Swann (University of Western Australia) the energy of electrons scattered by silver with surface contamination.

The sixth Australian Spectroscopy Conference will be held in Brisbane in 1967.
G. C. Barraclough
P. J. BLACK
D. J. DAVID
A. D. E. Pullin
J. S. Shannon

\section{BRITISH AID TO DEVELOPING COUNTRIES}

\begin{abstract}
$\mathrm{A}$
WHITE PAPER from the Ministry of Overseas Development *, outlining the work of the new Ministry, describes the policies by which the British Government

* Ministry of Overseas Development. Overseas Development: The Work of the New Ministry. (Cmnd. 2736.) Pp. 74. (London: H.M.S.O., 1965.) 5s. 6d. net.
\end{abstract}

proposes to be guided and the ways in which it hopes to help to meet the needs of the developing countries, without, however, specifying the extent of Britain's aid in particular periods. Successive chapters outline motives and objectives, the pace of overseas development, the transfer of resources and Britain's capacity to help--in 